Old Dominion University

ODU Digital Commons

Psychology Faculty Publications

Psychology

2003

\title{
Work and Family Variables as Related to Paternal Engagement, Responsibility, and Accessibility in Dual-Earner Couples with Young Children
}

Suzanne M. Nangle

Old Dominion University

Michelle L. Kelley

Old Dominion University, mkelley@odu.edu

William Fals-Stewart

Ronald F. Levant

Follow this and additional works at: https://digitalcommons.odu.edu/psychology_fac_pubs

Part of the Family, Life Course, and Society Commons, and the Social Psychology and Interaction Commons

\section{Repository Citation}

Nangle, Suzanne M.; Kelley, Michelle L.; Fals-Stewart, William; and Levant, Ronald F., "Work and Family Variables as Related to Paternal Engagement, Responsibility, and Accessibility in Dual-Earner Couples with Young Children" (2003). Psychology Faculty Publications. 82.

https://digitalcommons.odu.edu/psychology_fac_pubs/82

\section{Original Publication Citation}

Nangle, S. M., Kelley, M. L., Fals-Stewart, W., \& Levant, R. F. (2003). Work and family variables as related to paternal engagement, responsibility, and accessibility in dual-earner couples with young children. Fathering: A Journal of Theory, Research, and Practice about Men as Fathers, 1(1), 71-90. doi:10.3149/fth.0101.71 


\section{Work and Family Variables as Related to Paternal Engagement, Responsibility, and Accessibility in Dual-Earner Couples with Young Children}

SuZANne M. Nangle

Old Dominion University

WILLIAM FALS-STEWART

State University of New York at Buffalo
RONALD F. LEVANT

Nova Southeastern University

Fathers and mothers ( $N=75$ dual-earner couples) of preschoolaged children completed questionnaires that examined work and family variables as related to paternal involvement in three areas: engagement (i.e., directly interacting with the child), responsibility (i.e., scheduling activities and being accountable for the child's well-being), and accessibility (i.e., being available to the child but not in direct interaction). Fathers' reports of responsibility and accessibility were significantly predicted by structural variables and beliefs; however, fathers' reports of engagement were not predicted by work and family variables. Mothers' reports of work and family variables did not predict their reports of father involvement. These findings suggest that for fathers of young children, parental involvement appears mainly self-determined.

Key Words: father involvement, work and family variables

\footnotetext{
We would like to thank Cathy G. Cooke for her comments on an earlier version of this manuscript and the parents and daycare centers that took part in this research. William Fals-Stewart's effort on this study was supported in part by grants from the National Institute on Drug Abuse (R01DA12189-0A1) and the Alpha Foundation.
}

Correspondence concerning this article should be addressed to Michelle L. Kelley, Old Dominion University, Norfolk, Virginia 23529-0267. Electronic mail: mkelley@odu.edu.

Fathering, Vol. 1, No. 1, February 2003, pp. 71-90.

(C) 2003 by the Men's Studies Press, LLC. All rights reserved. 
NANGLE et al.

As a result of work and family changes, men are expected to be actively involved in all aspects of childcare. For many men, greater involvement in parenting reflects an internal value shift, such that active, involved fathering is central to their lives and their roles as fathers (e.g., see Barnett \& Hyde, 2001; Christiansen \& Palkovitz, 2001).

Paternal involvement is often operationalized in terms of time as the child's primary caregiver and the amount of child-related work fathers perform relative to their partners. Although these aspects of fathering are essential, they are not indicators of the quality of father-child interactions. Moreover, they do not measure unobservable and less enjoyable aspects of fathering, such as determining the appropriateness of various activities or planning for children's school or healthcare needs.

To understand the various forms that paternal involvement may take, Lamb and his colleagues defined three dimensions of fathering (Lamb, 1986; Lamb, Pleck, \& Levine, 1987). The first dimension, engagement, is defined as "time spent in actual one-on-one interaction with the child" (Lamb, 1986, p. 8). Direct contact, such as dressing the child or reading or playing a game together, are considered examples of engagement. Responsibility includes scheduling activities and being accountable for the child's welfare (e.g., arranging healthcare appointments, scheduling babysitting or childcare arrangements, buying the child's clothes). Child-related housework and non-interactive time spent with children are not considered engagement activities. Instead, these activities fall into a less intensive category of father involvement (i.e., accessibility). Accessibility includes non-direct involvement, such as being available to the child while cooking dinner or monitoring the child's play.

The purpose of the present study was to examine associations between concurrent measures of work, couple, and parent variables and paternal engagement, responsibility, and accessibility. Work and family experiences of men, as well as those of their partners, may influence paternal involvement. Thus, we examined work and family variables as reported by fathers and mothers as related to fathers' involvement with their preschool children.

\section{WORK AND FAMILY RELATIONSHIPS}

More than two decades of research have demonstrated that work and family life are inextricably linked. Work schedules and job responsibilities place demands on parents that must be accommodated by the family (see Barnett \& Hyde, 2001; Edwards \& Rothbard, 2000, for reviews). The contemporary work-family conflict literature suggests two distinct elements, work interference with family (WIF) and family interference with work (FIW) (Frone, Yardley, \& Markel, 1997). Furthermore, research has demonstrated that the more hours mothers work per week outside the home, the more time fathers spend taking care of children (Beitel \& Parke, 1998; Bonney, Kelley, \& Levant, 1999; Pleck, 1997).

Few investigations have examined the ways in which men's work experiences affect father-child interactions; however, work obligations (i.e., work hours) are one of the most frequent reasons given by fathers for low levels of parental involvement (Haas, 1992). In general, the more hours men work per week, the less time they spend in childcare (Beitel \& Parke, 1998; Bonney et al., 1999), however, a recent 
study found no differences between mothers and fathers in the amount of time they spend with children on weekends (Yeung, Sandberg, David-Kean, \& Hofferth, 2001).

It is important to note that hours in paid employment (e.g., Bernas \& Major, 2000) and, particularly, excessive work hours (Voydanoff \& Donnelly, 1999) are associated with job stress. Crouter, Bumpus, Head, and McHale (2001) found that father-adolescent relationships suffer as a result of the combination of long work hours and feelings of stress due to work overload. Especially for young fathers, presumably at a point early in their lives when career goals have not been met, the need for career investment may compete with family responsibilities. Clearly, job demands and particularly overwork may result in work-family conflict and reduce the time and energy men have for their children.

Job stress also places stress on the marital relationship (e.g., Kinnunen, Gerris, \& Vermulst, 1996). Kinnunen and colleagues found the more job stress reported by fathers, the more likely they were to report problem behaviors in their children. Although not all studies have demonstrated a relationship between fathers' participation in childcare and their reports of marital satisfaction (e.g., Ozer, Barnett, Brennan, \& Sperling, 1998), most investigators have reported positive marital experiences are associated with higher levels of fathers' involvement (Levy-Shiff \& Israelashvili, 1988). Women report higher relationship satisfaction when their partners are highly participatory in childcare (Bonney et al., 1999; Harris \& Morgan, 1991; Ozer et al., 1998). Harris and Morgan (1991) found that wives' marital satisfaction was in part dependent on their husbands' involvement in fathering. Viewed from a family systems framework, positive emotional interactions with spouses may affect the partners' state of mind and reinforce their desire to be involved in all aspects of the family life (e.g., Aldous, Mulligan, \& Bjarnason, 1998). For women in dual-earner couples, their partners' participation in childcare may reduce their feelings of role overload.

\section{BELIEFS ABOUT FATHERING}

It is important to recognize that beliefs parents have about children and cognitions about their role as parents influence parent-child interactions, parenting practices, and how parents carry out parental responsibilities (e.g., Goodnow, 2002; Sigel \& McGillicuddy-De Lisi, 2002). In fact, it is widely accepted that there are multilevel influences on child development. That is, parental cognitions influence factors such as parenting behavior that in turn affect child outcomes. For instance, men's commitment to and identification with the fatherhood role has been shown to be a significant predictor of the level of paternal involvement (Fox \& Bruce, 2001). Fathers with less traditional gender role beliefs and men who view fathers as critical for children's development are more involved in the day-to-day care of children than fathers with more traditional beliefs (e.g., Aldous et al., 1998; Beitel \& Parke, 1998; Costigan \& Cox, 2001; Crouter \& Manke, 1997; see Pleck, 1997). Moreover, wives' attitudes about their husbands' potential as competent caregivers influence the degree to which their husbands value the nurturing role (Rane \& McBride, 2000), and progressive gender role beliefs by women are associated with higher levels of paternal 
NANGLE et al.

involvement (Baruch \& Barnett, 1981; Beitel \& Parke, 1998; Hoffman \& Moon, 1999; Marsiglio, 1991). A number of researchers have noted roles fathers play in family life are interdependent with those of their spouses (e.g., Palkovitz, 1984). For instance, because women with more traditional gender role beliefs may perceive childcare as a primary role in the family, men whose spouses have traditional beliefs may be less involved in childrearing.

\section{PATERNAL ENGAGEMENT, RESPONSIBILITY, AND ACCESSIBILITY}

Relative to predictors of fathers' time with their children, we know less about what influences the quality of father-child interactions and why men take responsibility for necessary but less enjoyable aspects of fathering (Parke, 1996). The purpose of the present study was to examine associations between work and family variables in a sample of dual-earner couples as related to multiple dimensions of father involvement (i.e., engagement, responsibility, and accessibility). Only recently have investigators begun to explore the multi-dimensional nature of fathering (Fagan \& Iglesias, 1999; McBride \& Rane, 1997; Rane \& McBride, 2000). Importantly, these dimensions of fathering may not be mutually exclusive. Thus, we hypothesized that fewer hours in paid employment, less job stress, less work-family conflict, higher marital satisfaction, less marital conflict, and more progressive beliefs about the degree to which fathers should be involved in childrearing would predict greater paternal involvement across all three dimensions. We also expected that women's reports would predict their partners' involvement. That is, we expected that women who reported more hours in paid employment, less job stress, less work-family conflict, higher marital satisfaction, less marital conflict, and more progressive beliefs about fathering would have partners that were more involved in fathering.

Men and women in dual-income couples differ from single-wage couples in important ways (see Volling \& Belsky, 1991). Also, couples who choose centerbased childcare may differ from those who choose noncenter-based childcare (e.g., Hertz \& Furguson, 1996), and younger children are less self-sufficient and require more direct care than older children. At the same time, due to developmental changes in children, fathers who were less involved during their children's infancy may be drawn into parenting during children's toddler and preschool years (Woodworth, Belsky, \& Crnic, 1996). Thus, dual-earner couples with preschool-aged children attending center-based childcare were selected for the study.

\section{METHOD}

\section{PARTICIPANTS}

Respondents were 75 couples with preschool-aged children $(M=2.5$ years, $S D=1.1$ months, Range $=12$ to 48 months). There were 39 boys and 36 girls. All children were enrolled full-time at one of several licensed childcare centers in southeastern Virginia. The childcare centers served predominantly middle- and upper-middle-class families.

The mean age of the fathers was 35.5 years $(S D=5.5$; Range $=20$ to 44$)$. The education of the fathers was as follows: $12(16 \%)$ were high school graduates or less; 
27 (36\%) had attended college; $15(20 \%)$ were college graduates; and $20(27 \%)$ held graduate degrees. Information on education was missing for one father. Fathers worked an average of 46.3 hours per week $(S D=14.2)$. Sixty $(80 \%)$ men were European American; nine (12\%) were African American; two (3\%) were Latino; one (1\%) was Asian American; data on race/ethnicity were missing for three fathers. Mean family income was $\$ 67,590$ per year $(S D=\$ 34,350$; Range $=\$ 26,000$ to $\$ 200,000)$.

The mean age of the mothers was 32.8 years $(S D=5.5$; Range $=20$ to 44$)$. Mothers' education was as follows: seven (9\%) had completed high school or less; $23(31 \%)$ had attended college; 26 (35\%) were college graduates; and 18 (24\%) held graduate degrees. Information on education was missing for one mother. Mean hours worked outside of the home was 35.5 hours $(S D=13.1)$. Fifty-six mothers $(74.7 \%)$ were European American, 11 (15\%) were African American, two (3\%) were Latino, and one (1\%) was Asian American. Information on race/ethnicity was missing for five mothers. All couples were the child's biological parents and were living together at the time of the study (68 couples were married, five were cohabitating, marital status was missing for two couples). ${ }^{1}$ The average length of marriage/relationship was 7.4 years $(S D=4$ years). The majority of families $(88 \%)$ had two children. Families with more than one child attending the childcare center in the specified age range were given instructions for selecting the "target" child (i.e., if the first letter of the last name was between $A$ and $L$, families selected the youngest child; if the first letter of the last name was between $M$ and $Z$, families selected the oldest child). In some cases, administrative personnel at the daycare centers did not know whether parents met the study criteria (both parents were living in the home and employed at the time of the survey). In addition, some children had siblings in the age range attending the daycare center; therefore, it was not possible to calculate an accurate rate of return.

\section{OverVIEW OF MEASURES}

Parents completed a packet of questionnaires that assessed men's involvement with children, couples' beliefs about appropriate behavior for men, hours worked outside the home per week by each parent, perceptions of work-family conflict, marital satisfaction, and marital conflict in the presence of the child.

Paternal Index of Childcare Inventory (PICCI; Radin \& Goldsmith, 1985). Frank and Livington (2000) modified the original PICCI instrument. For the purposes of the present study, the PICCI was further modified to include questions from McBride's Paternal Responsibility Scale (McBride \& Mills, 1993). Our goal was to assess father involvement in three areas: engagement (i.e., direct interaction of the father with the child in common activities); responsibility (e.g., taking responsibility for the day-to-day welfare and needs of the child), and accessibility (e.g., being available but not in direct contact with the child). Before administering the questionnaire to study participants, the measure was piloted with college-student parents of young children, and minor modifications were made. The final father involvement instrument consisted of 40 items (12 engagement, 18 responsibility, and 12 accessi- 


\section{NANGLE et al.}

bility items, respectively). Engagement items included: "Reads to child," "Plays with child outdoors," and "Bathes the child." Responsibility statements included the following: "Determines appropriate activities for the child," "Takes child to preventative healthcare appointments," and "Buys child's clothes." Accessibility items included: "Is available to the child while cooking dinner," "Monitors child while he/she is playing," and "Is available to the child if he/she becomes upset." Each item was rated using the following five-point scale: $1=$ Mother always does, $2=$ Mother usually does, 3 = Father and mother equally do, $4=$ Father usually does, and $5=$ Father always does. Scores on the Engagement domain ranged from 24 to 43 for fathers and 21 to 41 for mothers, $(M$ [Fathers] $=34.7, S D=3.5 ; M$ [Mothers] $=32.9$, $S D=3.8)$. The range of scores on the accessibility domain was 17 to 34 for fathers and 13 and 32 for mothers, $(M$ [Fathers] $=28.8, S D=2.8 ; M$ [Mothers] $=26.8, S D=$ $4.1)$. For the responsibility domain scores ranged from 25 to 59 and 23 to $57,(M$ $[$ Fathers $]=41.9, S D=8.5 ; M$ [Mothers] $=46.1, S D=7.1)$. Alphas were .77 and .74 for engagement, .84 and .87 for responsibility, and .72 and .81 for accessibility for fathers and mothers, respectively.

Beliefs Concerning the Parental Role Scale (BCPR; Bonney \& Kelley, 1996). The BCPR is a 26-item scale that measures an individual's beliefs about each parent's role in childcare. Parents were asked to report their beliefs on both the role of the father (e.g., "It is important for fathers to spend quality time [one-on-one] with their child[ren] every day.") and the role of the mother (e.g., "It is more important for a mother rather than a father to stay home with an ill child."). Items were scored using a five-point scale ranging from $1=$ Agree strongly to $5=$ Disagree strongly. The mean score for fathers was 109.0 for fathers $(S D=12.1$; Range $=56.0$ to 126.0); the mean score for mothers was $112.5(S D=11.7$; Range $=56.0$ to 126.0$)$. The BCPR has been reported as both a reliable and valid measure of beliefs regarding a parent's role in childcare. Alphas of .87 for fathers and .80 for mothers were reported in a recent study of dual-income families with young children (Bonney et al., 1999), and .84 for fathers and .84 for mothers in the present research.

Job Stress (Bernas \& Major, 2000). Parents independently completed a 12-item questionnaire assessing perceptions of job stress. Items were scored using a fivepoint scale ranging from $1=$ Strongly agree to $5=$ Strongly disagree. Sample items include: "My working environment is very stressful" and "I have unwanted stress as a result of my present job." Participants' scores ranged from 1.0 to 4.64 for fathers and 1.0 to 5.00 for mothers. The mean score reported was $2.83(S D=.85)$ for fathers and $2.91(S D=.89)$ for mothers. Bernas and Major (2000) reported an alpha of .95; alphas for the present study were .94 for fathers and .84 for mothers.

Work-Family Conflict (Kopelman, Greenhaus, \& Connelly, 1983). Both parents completed a four-item measure assessing work interference with family (see Adams, King, \& King, 1996; see also Gutek, Searle, \& Klepa, 1991). An item from the work-family conflict scale is: "After work, I come home too tired to do some of the things I'd like to do." Items were scored using five-point scale ranging from $1=$ Strongly disagree to $5=$ Strongly agree. The mean score for fathers was $6.36(S D=$ 
1.93; Range $=2.0$ to 10.0$)$; the mean score for mothers was 7.34 (SD 1.96; Range $=$ 2.0 to 10.0). Participants' scores ranged from 2.0 to 10.0 for fathers and mothers. Alphas of .81 have been reported for the work-family conflict measure (Gutek et al., 1991); and alphas for the present study were .55 for fathers and .67 for mothers.

Kansas Marital Satisfaction Scale (KMS; Schumm et al., 1986). The KMS is a threeitem, self-report measure of satisfaction with one's spouse, marriage, and general relationship between spouses (e.g., "How satisfied are you with your marriage?"). Items are scored using a 7 seven-point Likert scale from $1=$ Extremely dissatisfied to $7=$ Extremely satisfied. . Scores are summed to yield an overall score of marital satisfaction. Mean scores on the KMS were 18.2 and 18.1 for fathers and mothers, respectively. Alphas were .96 and .92 for fathers and mothers, respectively.

O'Leary-Porter Scale (OPS; Porter \& O'Leary, 1980). The OPS is a 10-item measure assessing the frequency of parents openly arguing in the presence of their children (e.g., "Husbands and wives often disagree on the subject of discipline; how often do you and your spouse argue over disciplinary problems in this child's presence?"). Parents are asked to answer each item using a five-point Likert type scale ranging from $1=$ Never to $5=$ Very often . The range of scores was 11.0 to $38.0(M=18.5 ; S D$ $=5.0)$ and 12.0 to $33.0(M=19.1 ; S D=4.9)$ for fathers and mothers, respectively. Reliability for this measure has been reported as .86; test-retest reliability over a twoweek period was .96. Correlation of the O'Leary-Porter Scale with the Locke Wallace Marital Adjustment Scale has been reported at .63 using a clinical sample (Emery \& O'Leary, 1982) and .43 in a non-clinical sample (Emery \& O'Leary, 1984). For the present study, alphas were .83 for fathers and .79 for mothers.

Each parent also completed a demographic questionnaire that assessed parental age, education, number of children, and number of hours worked outside the home per week. Embedded in the demographic questionnaire was a question in which parents reported the percentage of time that they (and their partner) spent as the child's primary caregiver (the percentage of time mothers and fathers served as the primary caregiver had to total $100 \%$ ). This question made it possible to compare information from the present sample to that reported in previous research of this type.

\section{PROCEDURE}

A packet of questionnaires and envelopes was sent home with all children in the appropriate age range at each of the participating daycare centers. Attached to the outside of each packet was a coloring book and crayons. Inside the packet was a letter describing the study and two envelopes of questionnaires (one set of questionnaires for each parent). Parents were asked to complete the questionnaires independently, seal their responses in separate envelopes, place both sealed envelopes in a large envelope, and return the completed surveys to a specified box at the child's daycare center. 
NANGLE et al.

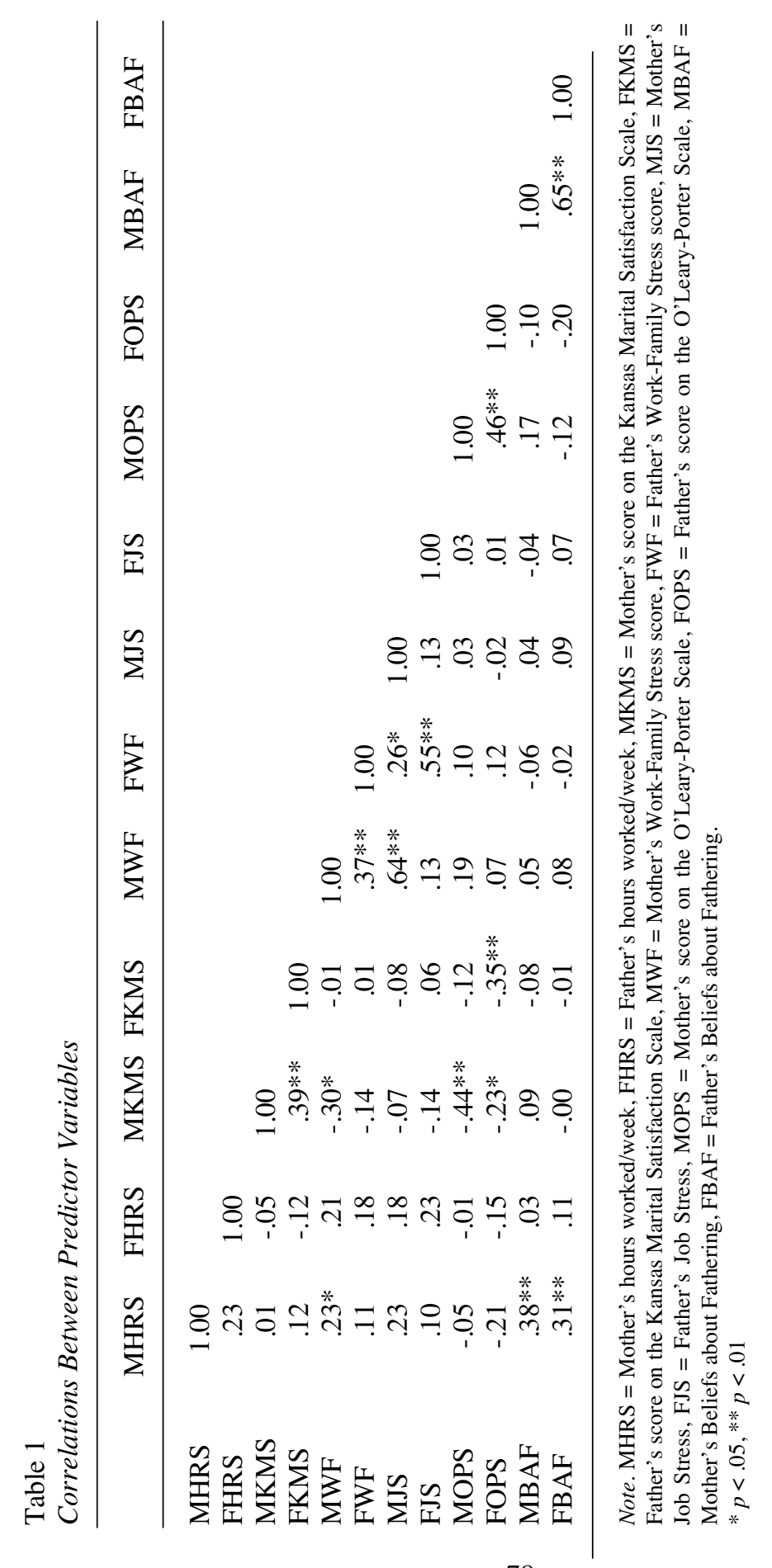


WORK AND FAMILY VARIABLES

\section{RESULTS}

\section{Correlations Between the Predictor Variables}

For the most part, the pattern of product-moment correlations between the predictor variables supported previous research (see Table 1). The more hours mothers worked outside the home per week, the less traditional were men's beliefs about fathers' involvement in childrearing activities, $r(73)=.31, p<.01$. In addition, the more hours women worked outside the home, the higher their work-family stress and the more they believed fathers should be involved in childcare, $r(74)=.23, p<.05, r$ $(74)=.38, p<.01$. Fathers' and mothers' beliefs about the degree to which fathers should be involved with children were significantly correlated, $r(74)=.65, p<.01$. This suggests that partners share similar beliefs regarding how involved men should be in the care of young children.

Mothers' and fathers' reports of marital satisfaction were significantly correlated, $r(73)=.39, p<.01$, as were their reports of overt marital conflict in front of the target child, $r(74)=.46, p<.01$. Mothers' reports of marital satisfaction were significantly, negatively correlated with their reports of marital conflict in front of the child, $r(74)=-.44, p<.01$. Similarly, fathers' reports of marital satisfaction were significantly and negatively correlated with their reports of dyadic conflict displayed in front of the target child, $r(73)=-.35, p<.01$.

Both fathers' and mothers' reports of work-family conflict correlated with their reports of job stress, $r(72)=.55, p<.05$, and $r(74)=.64, p<.01$, respectively. Fathers' work-family conflict was correlated with mothers' reports of work-family conflict, $r(73)=.37, p<.01$, and with mothers' reports of job stress, $r(73)=.26, p$ $<.05$.

\section{Correlations Between Partners' Reports of Engagement, Responsibility, AND ACCESSIBILITY}

Table 2 presents intercorrelations between fathers' and mothers' reports of fathers' engagement, responsibility, and accessibility behavior. As can be seen in the table, fathers' and mothers' reports for each of the subscales were moderately correlated $(r s=.53, .62$, and .45 for engagement, responsibility, and accessibility, respectively). Because several previous studies have examined the percentage of time fathers serve as the child's primary caregiver, we included each parent's reports of this variable in the table as well. Fathers' and mothers' reports of the percentage of time the father served as the child's primary caregiver were significantly correlated, $r(73)=.25, p<.05$.

\section{Correlations Between the Predictor Variables and Engagement, RESPONSIBILITY, AND ACCESSIBILITY}

Table 3 presents the correlations between the predictor variables and the three paternal involvement variables (i.e., engagement, responsibility, and accessibility). Mothers' marital satisfaction was significantly and positively associated with their reports 
NANGLE et al.

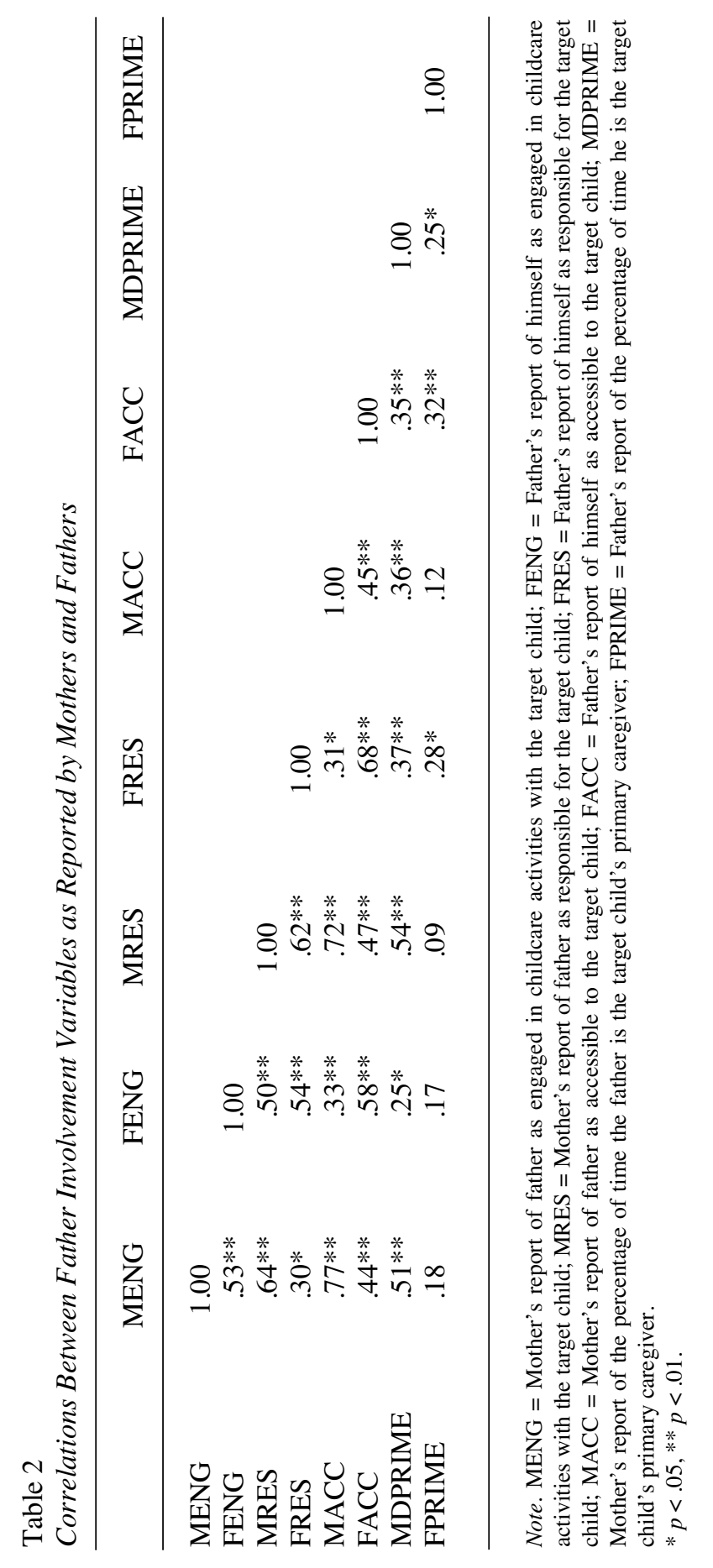

80 
WORK AND FAMILY VARIABLES

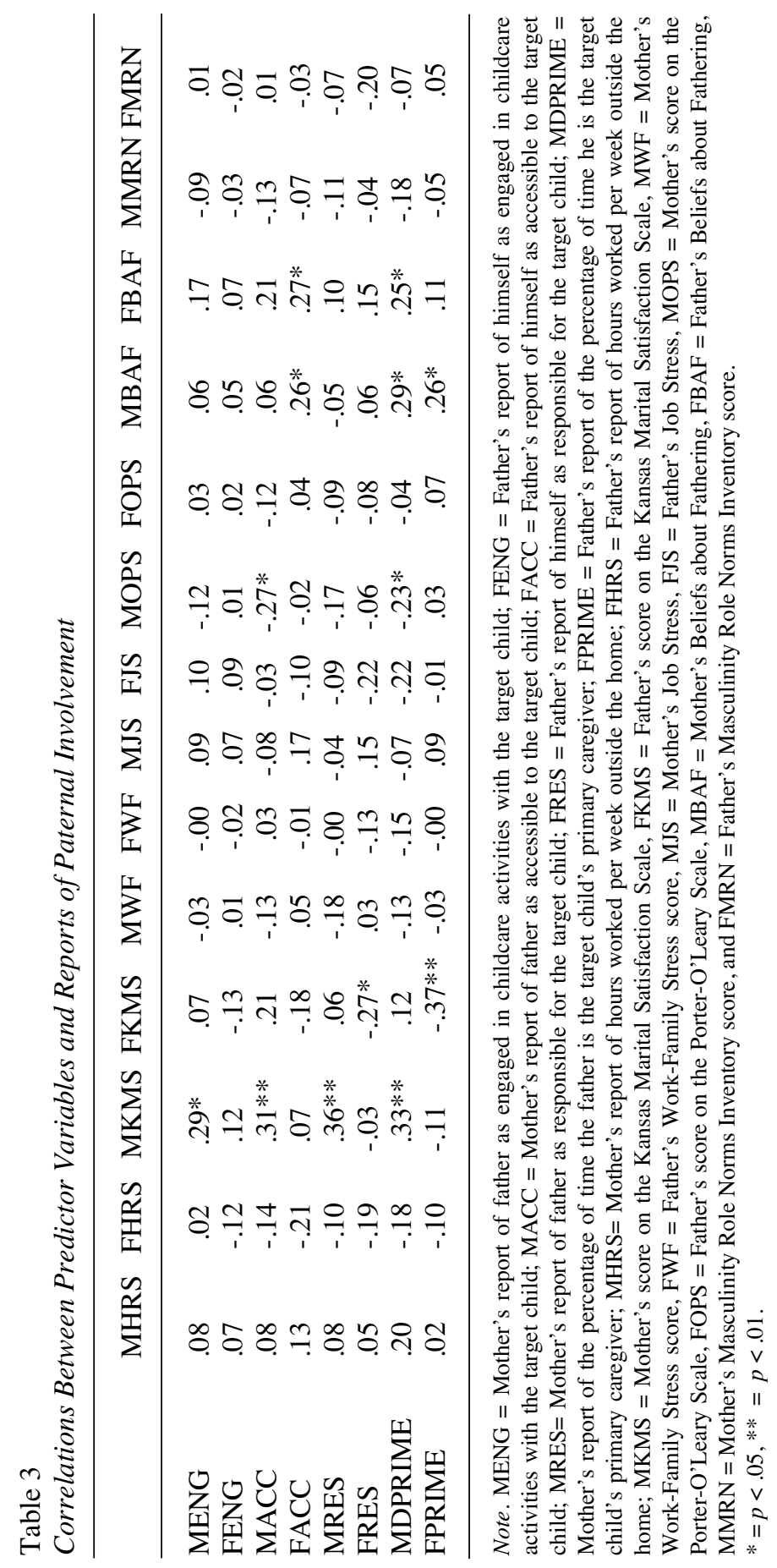


NANGLE et al.

of all dimensions of fathering, $(r \mathrm{~s}=.29, .36$, and .31 , for engagement, responsibility, and accessibility, respectively). In addition, mothers' level of marital satisfaction was correlated with the percentage of time they reported the father spent as the child's primary caregiver, $r(74)=.33, p<.01$. Conversely, fathers' level of marital satisfaction was significantly and negatively related to both their reports of the degree to which they took responsibility for the target child, $r(73)=-.27, p<.05$, and the percentage of time they served as the child's primary caregiver, $r(72)=-.37$, $p<.01$.

Mothers' reports of overt marital conflict in the presence of the target child were significantly and negatively associated with mothers' reports of fathers' accessibility, $r(75)=-.27, p<.05$, and the percentage of time mothers reported fathers served as the child's primary caregiver, $r(75)=-.23, p<.05$.

Mothers' reports of their beliefs regarding how involved fathers should be in childrearing were significantly and positively related to fathers' reports of their accessibility to the target child, $r(74)=.26, p<.05$. That is, more progressive beliefs regarding a father's role in childcare were associated with fathers' accessibility to children. In addition, more progressive beliefs about fathering (as reported by mothers) were associated both with women's and men's reports of the percentage of time the father served as the child's primary caregiver, $r(75)=.29, p<.05 ; r(73)=.26, p$ $<.05$, for mothers and fathers, respectively. Fathers' reports of more progressive beliefs about fathering roles were significantly and positively correlated with their reports of accessibility to the target child, $r(74)=.27, p<.05$. In addition, fathers' reports of more progressive gender role beliefs were significantly correlated to mothers' reports of fathers' time as the child's primary caregiver, $r(74)=.25, p<.05$.

\section{RESUlTS OF REGRESSION ANALYSES}

Six regression analyses were conducted to examine the degree to which the number of hours mothers and fathers worked outside the home, marital satisfaction, conflict in front of children, job stress, work-family conflict, and beliefs about fathers' roles in childcare predicted fathers' involvement (i.e., engagement, responsibility, and accessibility). Mothers' and fathers' variables were examined separately. Mothers' and fathers' scores on father engagement, responsibility, and accessibility served as the dependent variables.

As shown in Table 4, collectively the variables accounted for $20 \%$ of the variance in fathers' reports of childcare responsibility, $F(6,68)=2.83, p<.05$. Significant predictors of father responsibility were fathers' reports of marital satisfaction $(\beta$ $=-.33$ ) and the number of hours worked outside the home per week $(\beta=-.23)$. Collectively, the variables accounted for $18 \%$ of the variance in fathers' reports of accessibility to the child, $F(6,68)=2.41, p<.05$. Significant predictors of father accessibility were the number of hours fathers worked outside the home per week ( $\beta$ $=-.26)$ and beliefs about fathering $(\beta=.30)$. Specifically, the more progressive men's beliefs about fathers' roles, the higher their accessibility scores. The regression predicting father engagement was not significant. Moreover, regressions predicting mothers' reports of fathers' engagement, responsibility, and accessibility from mothers' work and family variables were not significant (see Table 5). 
WORK AND FAMILY VARIABLES

Table 4

Results of Regression Analyses Predicting Fathers' Reports of Paternal Engagement, Responsibility, Accessibility, and Percentage of Time as the Child's Primary Caregiver

\begin{tabular}{|c|c|c|c|c|c|}
\hline Variable & Beta & $R$ & $R^{2}$ & $F$ & Sig. \\
\hline \multicolumn{6}{|l|}{ Fathers' Reports of: } \\
\hline Engagement & & .25 & .06 & .80 & .615 \\
\hline FKMS & -.162 & & & & .205 \\
\hline FHRS & -.173 & & & & .168 \\
\hline FBAF & .066 & & & & .585 \\
\hline FWFC & -.082 & & & & .566 \\
\hline FOPS & -.033 & & & & .800 \\
\hline FJS & .176 & & & & .225 \\
\hline Responsibility & & .45 & .20 & 2.83 & .016 \\
\hline FKMS & -.327 & & & & .007 \\
\hline FHRS & -.234 & & & & .046 \\
\hline FBAF & .146 & & & & .195 \\
\hline FWFC & .033 & & & & .804 \\
\hline FOPS & -.192 & & & & .115 \\
\hline FJS & -.180 & & & & .177 \\
\hline Accessibility & & .42 & .18 & 2.41 & .036 \\
\hline FKMS & -.184 & & & & .126 \\
\hline FHRS & -.256 & & & & .032 \\
\hline FBAF & .304 & & & & .009 \\
\hline WFC & .099 & & & & .459 \\
\hline FOPS & -.003 & & & & .978 \\
\hline FJS & -.104 & & & & .440 \\
\hline \multicolumn{6}{|l|}{$\%$ of Time as Child's } \\
\hline Primary Caregiver & & .39 & .15 & 2.00 & .077 \\
\hline FKMS & .134 & & & & .271 \\
\hline FHRS & -.138 & & & & .249 \\
\hline FBAF & .278 & & & & .018 \\
\hline FWFC & -.018 & & & & .893 \\
\hline FOPS & .039 & & & & .756 \\
\hline FJS & -.198 & & & & .151 \\
\hline
\end{tabular}

Note . Fathers' scores on KMS = Kansas Marital Satisfaction Scale, HRS = Hours worked per week outside of the home, BAF = Beliefs About Fathering Scale, WFC = Work-Family Conflict Scale, OPS = O'Leary-Porter Scale, JS = Job Stress Scale. 
NANGLE et al.

Table 5

Results of Regression Analyses Predicting Mothers' Reports of Paternal Engagement, Responsibility, Accessibility, and Percentage of Time as the Child's Primary Caregiver

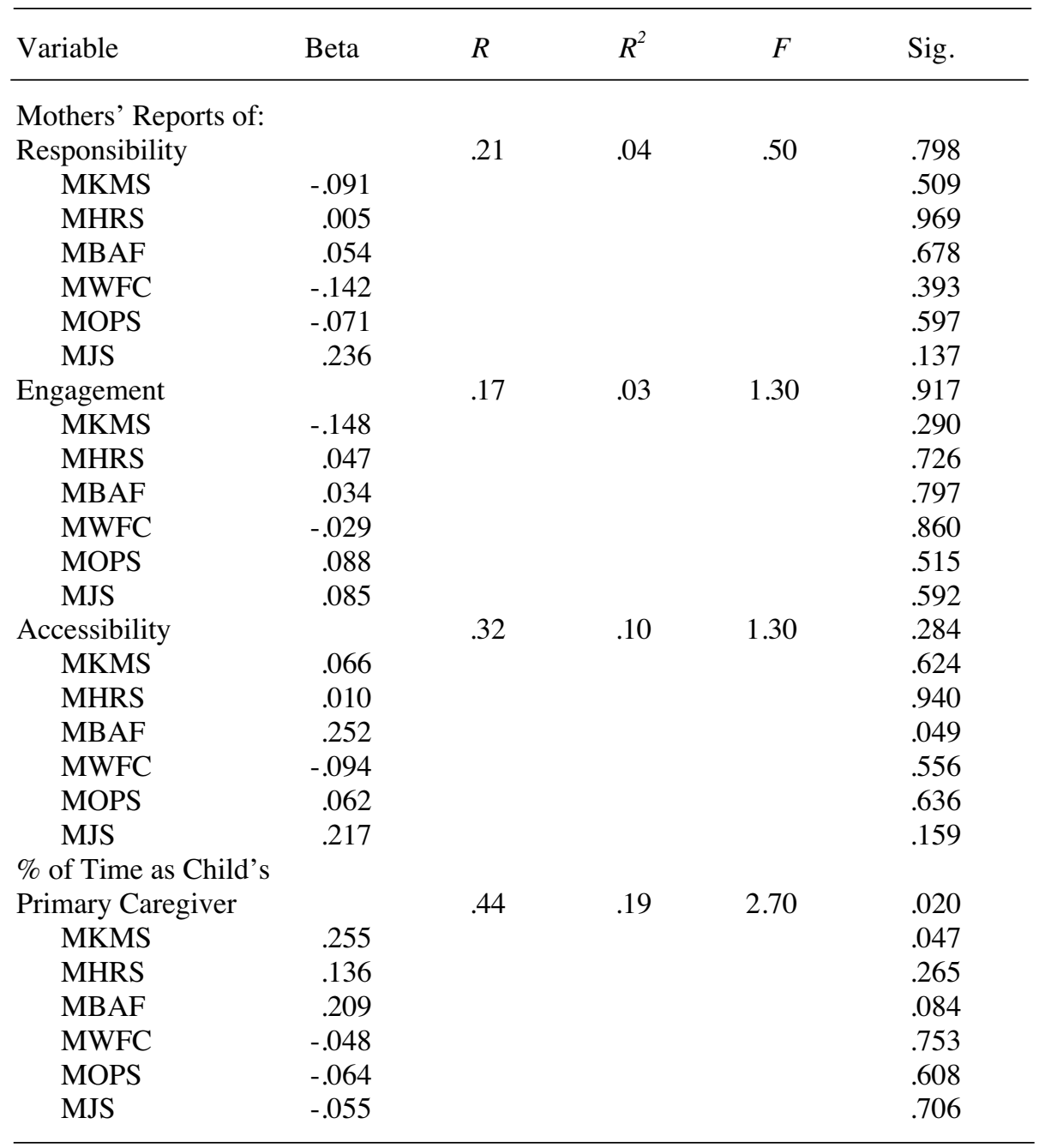

Note. Mothers' scores on KMS = Kansas Marital Satisfaction Scale, HRS = Hours worked per week outside of the home, BAF = Beliefs About Fathering Scale, WFC = Work-Family Conflict Scale, OPS = O'Leary-Porter Scale, JS = Job Stress Scale.

As noted earlier, several previous studies have used the "percentage of time" that fathers served as the child's primary caregiver as the dependent measure. Thus, two regression analyses were conducted with fathers' reports of the percentage of time they served as the child's primary caregiver and mothers' reports of the percentage of 
time fathers served as the primary caregiver as the dependent variables. There was a tendency for fathers' reports of work and family variables to predict men's reports of the percentage of time they served as the child's primary caregiver, $F(6,68)=2.0, p$ $<.10$. Specifically, more progressive beliefs about fathers' roles predicted men's reports of time spent as the child's primary caregiver $(\beta=.28)$. Mothers' reports of the percentage of time fathers served as the child's primary caregiver were predicted by their reports of work and family variables, $F(6,68)=2.71, p<.05$. Specifically, marital satisfaction significantly predicted mothers' reports of the percentage of time that fathers served as the child's caregiver $(B=.26)$. Also, there was a tendency for women's beliefs about fathers' roles to predict the percentage of time mothers reported fathers served as the child's primary caregiver $(\beta=.21)$.

\section{DISCUSSION}

Our results demonstrated that men's beliefs about the degree to which fathers should be involved in childrearing significantly predicted their reports of accessibility to children. In fact, men's beliefs about fathering predicted accessibility as measured by their reports of child monitoring behaviors and the percentage of time they reported that they were the child's primary caregiver. Consistent with previous research (e.g., Fox \& Bruce, 2001), these findings suggest that, for men in dualincome couples, their beliefs about fathering may be central, and in fact predict the degree to which they are available to their preschool-age children. Moreover, the vast majority of research has focused on what fathers $d o$ for their children; however, these results suggest that men's availability to their children is influenced by men's beliefs about the appropriateness of fathers' involvement with their children.

Interestingly, mothers' expectations for the extent to which fathers should be involved in childrearing were only correlated to two measures of men's availability to their children (i.e., mothers' reports of fathers' accessibility and mothers' reports of the percentage of time fathers served as the child's primary caregiver). A number of investigators have noted that for many men their internal values have shifted such that fathering is a central part of their lives (e.g., Levant, 1992). Results from the present study suggest that for married men with very young children paternal involvement is largely self-determined. Again, these findings suggest that men's beliefs are essential for understanding men's involvement with children and in family life.

As expected, mothers' reports of fathers' engagement, responsibility, accessibility, and the percentage of time fathers' served as the child's primary caregiver were significantly and positively correlated with women's reports of marital satisfaction. Our findings support the growing body of research suggesting that fathers' involvement with their children may reflect back positively on women's marital satisfaction (e.g., Harris \& Morgan, 1991).

In contrast to what was predicted, higher marital satisfaction as reported by men was negatively related to fathers' reports of their day-to-day responsibility for children's needs and activities. It should be noted that on average fathers worked 46 hours per week in paid employment, and that the number of hours fathers worked in paid employment was typically 10 hours more per week than their spouses. Also, in 
NANGLE et al.

$48 \%$ of families men were the family's main financial providers, in approximately $40 \%$ of families both partners contributed equally to the family's finances, and in $12 \%$ of families, women were the family's main financial providers. For many men, hours in work and ambition to advance in one's career are fundamental to their selfimages (Hochschild, 1997). We did not measure job attachment directly. However, it may be that men had considerable work attachment and presumably felt high levels of responsibility for their family's financial well-being. Although we cannot make causal statements based on our data, it is possible that for young fathers having a partner that assumes more responsibility for the day-to-day care of very young children may reduce the stress between work and family responsibilities and be associated with marital satisfaction.

It should be noted that both fathers and mothers reported that fathers were highly accessible to their children. In fact, because the percentage of time mothers and fathers serve as the child's primary caregiver is often an outcome measure in this type of research, parents were queried about this issue. On average, fathers reported that they were the child's primary caregiver approximately $46 \%$ of the time, whereas mothers' reported that fathers were the child's primary caregiver approximately $37 \%$ of the time. This finding is especially significant given that early childhood is a critical point for the development of parent-child attachment and for establishing men's active participation throughout their children's lives. Also, these results suggest that men are slowly moving toward equal participation with their wives in childcare.

As expected, the number of hours men worked in paid employment predicted both men's reports of responsibility for their children's activities and needs and their accessibility to their children. It is important to recognize that the parental responsibility measure assessed many aspects of childcare responsibility. Clearly, additional research is needed to examine variables that predict paternal responsibility and how mothers and fathers negotiate childcare tasks.

Importantly, both responsibility and accessibility reflect more quantifiable aspects of fathering. Interestingly, we were unable to predict fathers' or mothers' reports of paternal engagement (i.e., a more qualitative aspect of father involvement). Moreover, with one exception (mothers' marital satisfaction was related to mothers' reports of paternal engagement), there were no significant correlates of fathers' or mothers' reports of paternal engagement. It is possible that parents are less able to estimate more qualitative aspects of fathering. An alternative explanation is that while engagement items were designed to measure behaviors that are typically considered more characteristic of the quality of parent-child interaction, observational versus self-report data may be needed to assess this aspect of fathering. It is also possible that variables not examined in the present research may predict father engagement with their young children.

In many cases, mothers' and fathers' work variables were correlated in the expected direction (e.g., fathers' job stress was correlated with fathers' work-family conflict, mothers' work hours were correlated with mothers' work-family conflict, mothers' job stress was correlated with mothers' work-family conflict). However, job stress and work-family conflict were not associated with fathers' or mothers' reports of father involvement. Ransom (2001) found that fatherhood responsibilities were often organized around the demands of the workplace and that men whose 
fatherhood responsibilities were neither negotiable nor discretionary tended to be men whose career goals had already been met. Additional research should address the degree to which having met one's career goals influences parenting. It is also important to recognize that alphas for the work-family conflict measure were lower than reported in previous research (Gutek et al., 1991), which may have accounted for lack of relationships with this construct.

The present study has a number of methodological strengths, including the use of several well-established, psychometrically sound measures. Also, we attempted to reduce the heterogeneity of the sample so that more accurate statements about the nature of relationships in two-parent, dual-earner, predominantly middle- to uppermiddle-income couples with preschool children would be possible.

A number of limitations should also be considered. We examined the flow from work and family variables to father involvement; however, all data were collected contemporaneously. Therefore, we cannot infer causality from the present cross-sectional data. Also, while all children were between one and four years of age, especially for families with older children, the direction of effects may be best characterized as transactional. While the measure of work-family conflict employed was correlated with a number of variables in expected directions, it is important to note that this measure had low internal consistency in this study.

In addition, these findings should not be construed as generalizable to singleincome or single-parent families or dual-earner couples who choose noncenter-based options for childcare. Moreover, information was not collected on the length of time that children had attended childcare. Time in childcare may affect parents' stress at home and work. Also, families had little incentive for participation, and we were unable to determine a precise rate of return. Clearly, this study may suffer from participation bias common to this type of research. Related to this issue is that data were collected entirely through self-report questionnaires. Although there may be a tendency to present one's self in a favorable light, partners' reports of father involvement were significantly correlated. In addition, our results generally support previous research and suggest cognitive distortion is an unlikely explanation for these findings. Moreover, ideally, future research should examine four groups of parents: one in which both fathers and mothers are high in job attachment; both low in job attachment; one in which fathers are high, but mothers are low in job attachment; and one in which mothers are high, and fathers are low in job attachment.

In conclusion, our results suggest that the degree to which fathers in dual-earner couples are responsible for the day-to-day care of their preschool-age children and are accessible to their children in part appears determined both by structural variables, such as the number of hours men work in paid employment, marital satisfaction, and beliefs about fathering. These results also suggest that while fathers' reports of involvement in different areas of fathering appear related, examining variables that predict conceptually different dimensions of fathering may be an important and fruitful area of future research. 
NANGLE et al.

Note

1. Because preliminary analyses revealed that cohabiting couples did not differ from married couples and results yielded the same pattern of results when data from non-married couples were eliminated, a decision was made to include data from both married and non-married study parents.

\section{REFERENCES}

Adams, G.A., King, L.A., \& King D.W. (1996). Relationships of job and family involvement, family social support, and work-family conflict with job and life satisfaction. Journal of Applied Psychology, 81, 411-420.

Aldous, J., Mulligan, G.M., \& Bjarnason, T. (1998). Fathering over time: What makes the differences? Journal of Marriage and the Family, 60, 809-820.

Barnett, R.C., \& Hyde, J.S. (2001). Women, men, work, and family: An expansionist theory. American Psychologist, 56, 781-796.

Baruch, G.B., \& Barnett, R.C. (1981). Fathers' involvement in the care of their preschool children. Sex Roles, 7, 1043-1059.

Beitel, A., \& Parke, R. (1998). Parental involvement in infancy: The role of maternal and paternal attitudes. Journal of Family Psychology, 12, 268-288.

Bernas, K.H., \& Major, D.A. (2000). Contributors to stress resistance: Testing a model of women's work-family conflict. Psychology of Women Quarterly, 24, 2000.

Bonney, J.F., \& Kelley, M.L. (1996). Development of a measure assessing maternal and paternal beliefs regarding the parental role: The Beliefs Concerning the Parental Role Scale. Unpublished manuscript, Old Dominion University, Norfolk, VA.

Bonney, J.F., Kelley, M.L., \& Levant, R.F. (1999). A model of fathers' behavioral involvement in child care in dual-earner families. Journal of Family Psychology, 13, 401-415.

Christiansen, S.L., \& Palkovitz, R. (2001). Why the "good provider" role still matters: Providing as a form of paternal involvement. Journal of Family Issues, 22, 84-106.

Costigan, C.L., \& Cox, M.J. (2001). Fathers' participation in family research: Is there a self-selection bias? Journal of Family Psychology, 15, 706-720.

Crouter, A.C., Bumpus, M.F., Head, M.R., \& McHale, S.M. (2001). Implications of overwork and overload for the quality of men's family relationships. Journal of Marriage and the Family, 63, 404-416.

Crouter, A.C., \& Manke, B. (1997). The changing American workplace: Implications for individuals and families. Family Relations, 43, 117-124.

Edwards, J.R., \& Rothbard, N.P. (2000). Mechanisms linking work and family: Clarifying the relationship between work and family constructs. Academy of Management Review, 25, 178-199.

Emery, R.E., \& O'Leary, K.D. (1982). Children's perceptions of marital discord and behavior problems of boys and girls. Journal of Abnormal Child Psychology, $10,11-24$ 
Emery, R.E., \& O'Leary, K.D. (1984). Marital discord and child behavior problems in a nonclinic sample. Journal of Abnormal Child Psychology, 12, 411-420.

Fagan, J., \& Iglesias, A. (1999). Father involvement program effects on fathers, father figures, and their Head Start children: A quasi-experimental study. Early Childhood Research Quarterly, 14, 243-269.

Fox, G.L., \& Bruce, C. (2001). Conditional fatherhood: Identity theory and parental investment theory as alternative sources of explanation of fathering. Journal of Marriage and the Family, 63, 394-403.

Frank, R., \& Livington, K.E. (2000). Parenting partners: How to encourage dads to participate in the daily lives of their children. New York: St. Martin's Press.

Frone, M.R., Yardley, J.K., \& Markel, K.S. (1997). Developing and testing an integrative model of the work-family interface. Journal of Vocational Behavior, 50, 145-167.

Goodnow, J.J. (2002). Parents' knowledge and expectations: Using what we know. In M.H. Bornstein (Ed.), Handbook of parenting 2nd ed. Vol. 3: Being and becoming a parent (pp. 439-460). Mahwah, NY: Erlbaum Associates.

Gutek, B.A., Searle, S., \& Klepa, L. (1991). Rational versus gender role explanations for work-family conflict. Journal of Applied Psychology, 76, 560-568.

Haas, L. (1992). Equal parenthood and social policy. Albany, NY: State University of New York Press.

Harris, K.M., \& Morgan, S.P. (1991). Fathers, sons, and daughters: Differential parental involvement in parenting. Journal of Marriage and the Family, 53, 531-544.

Hertz, R., \& Furguson, F.I. (1996). Childcare choices and constraints in the United States: Social class, race, and the influence of family views. Journal of Comparative Studies, 27, 249-280.

Hochschild, A.R. (1997). The time bind: When work becomes home, and home becomes work. New York: Metropolitan Books.

Hoffman, C.D., \& Moon, M. (1999). Women's characteristics and gender role attitudes: Support for father involvement with children. The Journal of Genetic Psychology, 160, 411-418.

Kinnunen, U., Gerris, J., \& Vermulst, A. (1996). Work experience and family functioning among employed fathers with children of school age. Family Relations, $45,449-455$.

Kopelman, R.E., Greenhaus, J.H., \& Connelly T.F. (1983). Model of work, family, and interrole conflict: A construct validation study. Organizational Behavior and Human Performance, 32, 198-215.

Lamb, M.E. (Ed.). (1986). The changing roles of fathers. The fathers' role: Applied perspectives. New York: Wiley.

Lamb, M.E., Pleck, J., \& Levine, J.A. (1987). Effects of increased paternal involvement on fathers and mothers. In C. Lewis \& M. O'Brien (Eds.), Reassessing fatherhood: New observations on fathers and the modern family (pp. 109-125). Thousand Oaks, CA: Sage.

Levant, R.F. (1992). Toward the reconstruction of masculinity. Journal of Family Psychology, 5, 379-402. 
NANGLE et al.

Levy-Shiff, R., \& Israelashvili, R. (1988). Antecedents of fathering: Some further exploration. Developmental Psychology, 24, 434-440.

Marsiglio, W. (1991). Paternal engagement activities with minor children. Journal of Marriage and the Family, 53, 973-986.

McBride, B.A., \& Mills, G. (1993). A comparison of mother and father involvement with their preschool age children. Early Childhood Research Quarterly, 8, 457477.

McBride, B.A., \& Rane, T.R. (1997). Role identity, role investments, and paternal involvement: Implications for parenting programs for men. Early Childhood Research Quarterly, 12, 173-197.

Ozer, E.M., Barnett, R.C., Brennan, R.T., \& Sperling, J. (1998). Does childcare involvement increase or decrease distress among dual-earner couples? Women's Health: Research on Gender, Behavior, and Policy, 4, 284-311.

Parke, R. (1996). Fatherhood. Cambridge, MA: Harvard University Press.

Palkovitz, R., (1984). Parenting attitudes and fathers' interactions with their 5-month old infants. Developmental Psychology, 20, 1054-1060.

Pleck, J.H. (1997). Paternal involvement: Levels, sources, and consequences. In M. Lamb (Ed.), The role of the father in child development (3rd. ed., pp. 66-103). New York: Wiley.

Porter, B., \& O’Leary, K.D. (1980). Marital discord and childhood behavior problems. Journal of Abnormal Child Psychology, 8, 287-295.

Radin, N., \& Goldsmith, R. (1985). Caregiving fathers of preschoolers: Four years later. Merrill-Palmer Quarterly, 31, 375-383.

Rane, T.R., \& McBride, B.A. (2000). Identity theory as a guide to understanding fathers' involvement with their children. Journal of Family Issues, 21, 347-366.

Ransom, G. (2001). Men at work: Change-or not change? - in the era of the "new father." Men and Masculinities, 4, 3-26.

Schumm, W.R., Paff-Bergen, L.A., Hatch, R.C., Obiorah, F.C., Copeland, J.M., Meens, L.D., \& Bugaighis, M. (1986). Concurrent and discriminant validity of the Kansas Marital Satisfaction Scale. Journal of Marriage and the Family, 48, 381-398.

Sigel, I.E., \& McGillicuddy-De Lisi, A. V. (2002). Parent beliefs are cognitions: The dynamic belief systems model. In M.H. Bornstein (Ed.), Handbook of parenting 2nd ed. Vol. 3: Being and becoming a parent (pp. 485-508). Mahwah, NY: Erlbaum Associates.

Volling, B.L., \& Belsky, J. (1991). Multiple determinants of father involvement during infancy in dual-earner and single-earner families. Journal of Marriage and the Family, 53, 461-474.

Voydanoff, P., \& Donnelly, B. W. (1999). Multiple roles and psychological distress: The intersection of the paid worker, spouses, and parent roles with the role of the adult child. Journal of Marriage and the Family, 61, 725-738.

Woodworth, S., Belsky, J., \& Crnic, K. (1996). The determinants of fathering during the child's second and third years of life: A developmental analysis. Journal of Marriage and the Family, 58, 679-692.

Yeung, W., Sandberg, J.F., David-Kean, P.E., \& Hofferth, S.L. (2001). Children's time with fathers in intact families. Journal of Marriage and the Family, 63, 136-154. 